\title{
Hospital Pharmacy Preparedness and Pharmacist Role During Disaster in Saudi Arabia
}

\author{
Ahmed Aljabri $\mathbb{D}^{1,2}$ \\ Hussain Bakhsh' \\ Abeer Baageel ${ }^{3}$ \\ Sara Al-Nimari ${ }^{3}$ \\ Samah Alshehri ${ }^{1,4}$ \\ Bashayer Bakadam ${ }^{3}$ \\ Shaima Almasrahi ${ }^{3}$ \\ Hussam Kutbi ${ }^{\prime}$ \\ 'Department of Pharmacy Practice, \\ Faculty of Pharmacy, King Abdulaziz \\ University, Jeddah, 21589, Saudi Arabia: \\ ${ }^{2}$ Department of Pharmacy Practice, \\ Faculty of Pharmacy, University of Tabuk, \\ Tabuk, 7|49I, Saudi Arabia; ${ }^{3}$ Faculty of \\ Pharmacy, King Abdulaziz University, \\ Jeddah, 21589 , Saudi Arabia; ${ }^{4}$ College of \\ Pharmacy, University of Arizona, Tucson, \\ AZ, 8572I, USA
}

Background: In case of emergencies, the number and severity of mass casualties may exceed medical services resources. Saudi Arabia is prone to different disasters, and all medical resources should be ready and prepared to serve during disasters. Pharmacists are essential during disasters; however, their roles have not been well studied during disasters in Saudi Arabia.

Methods: An observational cross-sectional study targeted tertiary hospitals in Jeddah. An electronic survey, consisting of 34 questions, was developed and distributed to pharmacy directors or their representatives to investigate the hospital pharmacies' preparedness and pharmacist roles during disasters in the city of Jeddah.

Results: Six hospitals participated in the survey, with a $100 \%$ response rate. All respondents confirmed the presence of disaster plans involving pharmacy departments. Hospital committee consensuses determined which medication to stock in five hospitals (83.3\%). All six respondents (100\%) agreed that the following medication supplies were adequate in the event of disasters: analgesics, rapid sequence intubation medications (ie, sedatives and paralytics), respiratory medications, antimicrobials, and maintenance intravenous (IV) fluids. There was disagreement on the adequacy of wound infection prophylaxis, vasopressors/inotropes, antiemetic medications, ophthalmic medications, and antidotes for chemical weapons. There were discrepancies on pharmacist roles during disaster, but hospitals agreed on the following roles: maintain effective distribution and control, collaborate on medication management, and develop and maintain first-aid skills.

Conclusion: All included facilities have emergency preparedness plans for the hospitals and the pharmacy departments. However, the type and quantities of stocked medications, as well as pharmacist roles, are not well recognized. The results highlight the need for national guidance to enhance and support the preparedness of healthcare facilities.

Keywords: hospital pharmacy, mass casualty, disaster, pharmacist roles, emergency preparedness

\section{Introduction}

According to the World Health Organization (WHO), an emergency is defined as "a sudden occurrence demanding immediate action that may be due to epidemics, to natural, to technological catastrophes, to strife or to other man-made causes." ${ }^{\text {"1 }}$ During an emergency, the number and severity of mass casualties may exceed medical services resources, such as personnel and equipment. The causes of mass casualty are varied. For example, Saudi Arabia is prone to various types of emergencies, including natural disasters (eg, floods and sandstorms), human-made disasters (eg, terrorism acts), and Hajj (annual Islamic pilgrimage to Mecca) season -related disasters (eg, fires, floods,
Department of Pharmacy Practice, Faculty of Pharmacy, King Abdulaziz University,

Jeddah, 21589, Saudi Arabia

Tel +966I26400000/2II 46

Fax+966126951696

Email amaljabri@kau.edu.sa 
and pilgrim stampedes) that could remarkably affect a huge population and increase expenditures for medical and financial resources. ${ }^{2,3}$ The unique circumstances of disasters and emergencies are difficult to anticipate, which is the most logistical challenge. Hospitals should implement comprehensive emergency management plans that incorporate different departments, such as medicine, nursing, pharmacy, and administration.

Pharmacists have major influence in disaster preparedness and response, as they are involved in clinical and nonclinical roles. These roles were generally described in the literature via the American Society of Health System $(\mathrm{ASHP})^{4}$ and International Pharmaceutical Federation (FIP). ${ }^{5}$ During crises, pharmacists tend to be some of the most accessible healthcare professionals. Pharmacists' contributions during disasters have been discussed in previously published studies because pharmacists continuously and consistently participate in humanitarian efforts alongside other healthcare professionals. This participation was evident during the United States' 2001 anthrax crisis, Hurricane Katrina in 2005, and more recently, the global COVID-19 pandemic, during which pharmacists took on more elaborate roles, such as providing direct patient care, administering medications and immunizations, and triaging patients. ${ }^{6,7}$ According to Nazar Z and Nazar H, pharmacists' roles throughout a disaster are patient management, response integration, pharmaceutical supply, and policy coordination. ${ }^{6}$ Although the Center for Disease Control and Prevention (CDC) and many other health organizations issue guidance on how to deal with COVID-19, there is still is an urgent need to understand and evaluate the current practices of hospital pharmacies and pharmacists to develop a nationwide guidance for pharmacists during disasters. Currently, there is no national pharmacy organization recommendation that describes the role of pharmacist in emergency preparedness in Saudi Arabia. To our knowledge, this research represents the first attempt to describe pharmacist roles and the regional level of hospital pharmaceutical response preparedness in the kingdom of Saudi Arabia. The main aim of our study is to describe the current situation of pharmacy departments and pharmacists' roles in terms of emergency preparedness.

\section{Methods}

We conducted an observational cross-sectional study targeting tertiary hospitals in Jeddah. Before commencing the study, an ethical approval was obtained, as well as informed consents from all participants included in this study. An electronic survey was developed and emailed to pharmacy directors or their representatives after obtaining their contact information from the hospital websites. All pharmacy directors were interviewed and orientated to the survey to make sure there was consistent understanding of all survey items. Then, their answers were recorded electronically. The goal of the survey was to investigate hospital pharmacy preparedness, and the roles that pharmacists undertake during disasters in Jeddah.

The survey consisted of 34 questions: 22 multiple-choice questions and 12 questions formatted based on the Likert Scale, allowing five responses ranging from "strongly agree" to "strongly disagree." The survey focused on the following three main sections: (1) demographic characteristics of the hospital, pharmacy department, and the survey taker (nine questions); (2) hospital pharmacy emergency preparedness, including the existence of a disaster plan, presence of a disaster planning committee, frequency of disaster plan review, frequency of drills, quantity of medications, and adequacy of certain medication stocks in case of disasters; and (3) pharmacists' roles during disaster (including inventory management, patient management, response integration, and cooperation with healthcare providers). The questionnaire was validated by Awad and Cocchio, ${ }^{8}$ and the pharmacist roles were categorized using Setlak's classification scheme. ${ }^{9}$ The study analysis was performed using a descriptive statistic. IBM SPSS Statistics for Windows (Version 25.0. Armonk, NY: IBM Corp) was utilized, and a response summary was presented as numbers and percentages.

\section{Results \\ Hospital Pharmacy Emergency Preparedness}

Six hospitals participated in the survey, with a $100 \%$ response rate. Table 1 summarizes hospital, pharmacy department, and survey taker characteristics. Four hospitals were governmental $(66.7 \%)$, and one hospital was a university teaching hospital (16.7\%). There were four hospitals with bed capacity exceeding 600 beds $(66.7 \%)$ and two hospitals with licensed beds between 400 and 600 beds $(33.3 \%)$. The trauma center level varied between the hospitals. Three hospitals (50\%) had no nearby tertiary hospitals within a $10-\mathrm{km}$ radius. A decentralized pharmacy model was the most common pharmacy model (66.7\%). Pharmacy directors filled out the survey in three hospitals (50\%), associate directors in two hospitals $(33.3 \%)$, and a drug information pharmacist in one hospital (16.7\%). 
Table I Hospital, Pharmacy, and Survey Taker Characteristics

\begin{tabular}{|c|c|c|}
\hline \multicolumn{2}{|c|}{ Hospital Characteristics } & $\mathbf{N}(\%)$ \\
\hline \multirow[t]{3}{*}{ Type } & Governmental hospital & $4(66.67 \%)$ \\
\hline & University teaching hospital & I (I6.67\%) \\
\hline & Private hospital & I (I6.67\%) \\
\hline \multirow[t]{2}{*}{$\mathrm{N}$ of licensed beds } & $>600$ beds & $4(66.67 \%)$ \\
\hline & $400-600$ beds & $2(33.33 \%)$ \\
\hline \multirow[t]{3}{*}{$\mathrm{N}$ of licensed beds in the ED } & $60-90$ beds & $3(50.00 \%)$ \\
\hline & $30-60$ beds & $2(33.33 \%)$ \\
\hline & $<30$ beds & I (I6.67\%) \\
\hline \multirow[t]{4}{*}{ Level of trauma center } & Level 3 & $2(33.33 \%)$ \\
\hline & Level 2 & $2(33.33 \%)$ \\
\hline & Level I & I (I6.67\%) \\
\hline & None & I (I6.67\%) \\
\hline \multirow[t]{2}{*}{ Pediatric emergency } & Yes & $4(66.67 \%)$ \\
\hline & No & $2(33.33 \%)$ \\
\hline \multirow{3}{*}{$\begin{array}{l}\mathrm{N} \text { of tertiary hospitals within } 10 \mathrm{~km} \\
\text { radius }\end{array}$} & $3-4$ & I (I6.67\%) \\
\hline & $1-2$ & $2(33.33 \%)$ \\
\hline & None & $3(50.00 \%)$ \\
\hline \multicolumn{2}{|c|}{ Pharmacy department characteristics } & $\mathbf{N}(\%)$ \\
\hline \multicolumn{2}{|l|}{ Satellite/decentralized pharmacy } & $4(66.67 \%)$ \\
\hline \multicolumn{2}{|l|}{ Automated dispensing } & $3(50.00 \%)$ \\
\hline \multicolumn{2}{|l|}{ Centralized pharmacy } & $2(33.33 \%)$ \\
\hline \multicolumn{2}{|l|}{ Unit-based pharmacists } & $2(33.33 \%)$ \\
\hline \multicolumn{2}{|c|}{ Survey taker characteristics } & $\mathbf{N}(\%)$ \\
\hline \multirow[t]{3}{*}{ Position } & Pharmacy director & $3(50.00 \%)$ \\
\hline & Assistant/associate director & $2(33.33 \%)$ \\
\hline & Drug information pharmacist & I (16.67\%) \\
\hline \multirow[t]{3}{*}{ Education } & Doctor of pharmacy & $3(50.00 \%)$ \\
\hline & Master of science & $2(33.33 \%)$ \\
\hline & Bachelor of science in pharmacy & I (I6.67\%) \\
\hline
\end{tabular}

The survey showed that all hospitals have disaster planning committees, disaster preparedness plans, and disaster plans specifically implemented for the pharmacy departments (100\%). Pharmacists in all hospitals included in the study have active roles in writing emergency plans
$(100 \%)$. The disaster events that were included in the hospital plans were as follows: chemical (83.3\%), biological (50\%), natural disaster (50\%), radiological (50\%), and other mass casualty events (50\%). Only one hospital had systems shutdown and utilities shutdown plans (16.7\%). 
Five hospitals $(83.3 \%)$ conducted workshops to facilitate staff awareness of emergency preparedness, and all their staff had received an orientation to the disaster preparedness plan. Hospital committee consensuses determined which medication to stock in five hospitals (83.3\%), but the Saudi Central Board for Accreditation of Healthcare institution (CBAHI) and Joint Commission International (JCI) standards determined the medications for one hospital (16.7\%). Pharmacy departments were involved in mock disaster drills every six months in two hospitals (33.3\%), every 12 months in three hospitals (50\%), and every three months in one hospital (16.7\%).

Table 2 summarizes the hospitals' responses regarding the adequacy of stocked medications in the event of disasters. All respondents agreed that the following medications were adequate in the event of disasters (ranging from "strongly agree" to "agree"): analgesics, rapid sequence intubation medications (ie, sedatives and paralytics), respiratory medications, antimicrobials, and maintenance intravenous (IV) fluids. There was disagreement on the adequacy of wound infection prophylaxis, vasopressors and inotropes, antiemetic medications, ophthalmic medications, and chemical weapon antidotes in the event of disasters. Four (66.7\%) hospitals strongly agreed that the quantity of medication was sufficient to treat hospital employees and patients, and three (50\%) strongly agreed that there are processes to ensure care for already hospitalized patients.

\section{Pharmacist Role Descriptions}

Table 3 lists the roles of pharmacists in the event of disasters. Pharmacists are responsible for maintaining effective distribution and control of the inventory management system in all hospitals (100\%). Four hospitals $(66.7 \%)$ assign pharmacists to maintain procurement, storage, and restocking of medication and to develop a contingency plan for medication shortages. Three hospitals $(50 \%)$ rely on pharmacists to maintain contact of pharmaceutical manufacturers and wholesalers, and at two hospitals (33.3\%), pharmacist roles include ensuring that the pharmaceutical items are consistent with the plans.

Regarding patient management roles, all hospitals agreed that pharmacists should collaborate on medication management $(100 \%)$. The pharmacist is responsible for educating the public about therapies in four hospitals (66.7\%), acting to prevent panic and monitoring disease progression in three hospitals $(50 \%)$, and engaging in oneon-one patient counseling in two hospitals (33.3\%).

The response integration description roles showed the following. Pharmacists are required to develop and

Table 2 Hospital Responses on the Adequacy of the Stocked Medications to Treat the Expected Patients During Disasters

\begin{tabular}{|c|c|c|c|}
\hline Category & $\begin{array}{l}\text { Strongly Agree } \\
\text { N (\%) }\end{array}$ & $\begin{array}{l}\text { Agree } \\
\text { N (\%) }\end{array}$ & $\begin{array}{l}\text { Neutral } \\
\text { N (\%) }\end{array}$ \\
\hline Analgesics medications & $4(66.67 \%)$ & $2(33.33 \%)$ & $0(0.00 \%)$ \\
\hline Wound infection prophylaxis medications & $3(50.00 \%)$ & $2(33.33 \%)$ & I (16.67\%) \\
\hline Rapid sequence intubation (sedatives and paralytics) medications & $2(33.33 \%)$ & $4(66.67 \%)$ & $0(0.00 \%)$ \\
\hline Vasopressor/inotropic medications & $4(66.67 \%)$ & I (16.67\%) & I (I6.67\%) \\
\hline Antiemetics medications & $3(50.00 \%)$ & $2(33.33 \%)$ & I (16.67\%) \\
\hline Respiratory medications & $5(83.3 \%)$ & I (I6.67\%) & $0(0.00 \%)$ \\
\hline Ophthalmic medications & $2(33.33 \%)$ & $3(50.00 \%)$ & I (16.67\%) \\
\hline Chemical weapons' antidotes medications & $3(50.00 \%)$ & I (I6.67\%) & $2(33.33 \%)$ \\
\hline Antimicrobials medications & $3(50.00 \%)$ & $3(50.00 \%)$ & $0(0.00 \%)$ \\
\hline Maintenance IV fluids & $5(83.3 \%)$ & I (I6.67\%) & $0(0.00 \%)$ \\
\hline $\begin{array}{l}\text { Quantities of medication is adequate to treat hospital employees in addition to the } \\
\text { community }\end{array}$ & $4(66.67 \%)$ & $2(33.33 \%)$ & $0(0.00 \%)$ \\
\hline $\begin{array}{l}\text { Quantities of medication is adequate to ensure care is maintained for patients already in } \\
\text { the hospital }\end{array}$ & $3(50.00 \%)$ & $3(50.00 \%)$ & $0(0.00 \%)$ \\
\hline
\end{tabular}


Table 3 Pharmacists Role in the Event of Disasters

\begin{tabular}{|c|c|c|}
\hline \multicolumn{2}{|c|}{ Pharmacist Role } & \multirow{2}{*}{$\frac{\mathbf{N}(\%)}{6(100.00 \%)}$} \\
\hline Inventory Management System & Maintain effective distribution and control & \\
\hline & $\begin{array}{l}\text { Maintain procurement, storage and restock of } \\
\text { medication }\end{array}$ & $4(66.67 \%)$ \\
\hline & $\begin{array}{l}\text { Develop a contingency plan for medication } \\
\text { shortages }\end{array}$ & $4(66.67 \%)$ \\
\hline & $\begin{array}{l}\text { Maintain contact of pharmaceutical manufacturers } \\
\text { and wholesalers }\end{array}$ & $3(50.00 \%)$ \\
\hline & $\begin{array}{l}\text { Ensure that the pharmaceutical items are consistent } \\
\text { with the plans }\end{array}$ & $2(33.33 \%)$ \\
\hline \multirow[t]{5}{*}{ Patient Management Roles } & Collaborate on medication management & $6(100.00 \%)$ \\
\hline & Educate the public about therapies & $4(66.67 \%)$ \\
\hline & Act to prevent panic and fear & $3(50.00 \%)$ \\
\hline & Monitor disease progression & $3(50.00 \%)$ \\
\hline & Engage in one-on-one patient counseling & $2(33.33 \%)$ \\
\hline \multirow[t]{4}{*}{ Response Integration Description } & Develop and maintain first-aid skills & $6(100.00 \%)$ \\
\hline & $\begin{array}{l}\text { Assist in patient triage and cardiopulmonary } \\
\text { resuscitation (CPR) }\end{array}$ & $5(83.33 \%)$ \\
\hline & Become well informed about relevant topics & $3(50.00 \%)$ \\
\hline & Ensure proper deployment of drug & $2(33.33 \%)$ \\
\hline \multirow[t]{4}{*}{$\begin{array}{l}\text { Cooperation with Healthcare } \\
\text { Providers }\end{array}$} & $\begin{array}{l}\text { Collaborate with physicians in managing drug } \\
\text { therapy of victims }\end{array}$ & $5(83.33 \%)$ \\
\hline & $\begin{array}{l}\text { The provision of drug information to all } \\
\text { stakeholders }\end{array}$ & $4(66.67 \%)$ \\
\hline & Advise public health officials & $3(50.00 \%)$ \\
\hline & Volunteer in other health institutions in a disaster & I (I6.67\%) \\
\hline
\end{tabular}

maintain first-aid skills in all hospitals (100\%), assist in patient triage and cardiopulmonary resuscitation (CPR) in five hospitals $(83.3 \%)$, become well informed about relevant topics in three hospitals (50\%), and ensure proper deployment of medications in two hospitals (33.3\%).

Finally, the responses to the cooperation with healthcare provider roles showed that, during disasters, pharmacists are responsible for collaborating with physicians in managing victims' drug therapy in five hospitals $(83.3 \%)$, providing drug information to all stakeholders in four hospitals (66.7\%), advising public health officials in three hospitals $(50 \%)$, and volunteering in other health institutions when needed in one hospital (16.7\%).

\section{Discussion}

The major findings of this survey showed that all included hospitals have disaster planning committees in which pharmacists have active roles, disaster preparedness plans, and disaster plans specifically implemented for the pharmacy departments. However, there were discrepancies on the amount and type of stocked medications, as well as the pharmacist roles.

Jeddah has experienced an increased number of disasters in recent years, including the 2009 and 2011 floods that caused 172 deaths and cost approximately 3 billion USD. Moreover, approximately 1000 individuals died during the 2015 Hajj Stampede. ${ }^{10,11}$ These incidents highlighted the need to evaluate hospital preparedness in the 
event of disasters. The pharmacy department is a critical department within the hospital and is responsible for medication supply and utilization. Therefore, pharmacy departments must have an emergency preparedness plan to organize and coordinate efforts during disasters. To our knowledge, the current study is the first to evaluate the emergency preparedness of Jeddah's major hospitals. All hospitals participating in the survey have emergency preparedness plans in which pharmacy departments have active roles. Moreover, all hospitals have specific emergency preparedness in place for pharmacy departments in the event of disasters.

Awad and Cocchio evaluated the emergency preparedness of hospital pharmacies in New Jersey, and they found that all included hospitals had disaster plans. ${ }^{8}$ However, approximately half of the hospitals had no specific plans for the pharmacy departments. Moreover, $88 \%$ of pharmacy department were involved in disaster drills, compared to the $100 \%$ of pharmacy departments included in our survey who performed disaster drills at least annually. We believe that previous exposure to disasters in Jeddah during recent years have contributed to an overall increase in local hospitals' awareness of emergency preparedness because of the lessons learned through those experiences. Furthermore, the impact of these events at local and global levels might have contributed to our findings.

Although all pharmacy departments have specific emergency preparedness plans, there are inconsistent results on the types and quantities of stocked medications between the hospitals, and the majority rely on hospital committee consensus. This finding could raise some logistical issues because there is no established program on a national or regional level designed to resupply hospitals with the required medications and supplies during a disaster. The current findings highlight the need for a national program, such as the Strategic National Stockpiles operated by the CDC in the United States, to enhance and support healthcare facilities' preparedness by providing medications and supplies as needed during public health emergencies. ${ }^{12}$ Although the Saudi Arabia Ministry of Health recently established the National Health Emergency Operations Center, there is no official guidance or recommendation regarding the roles of pharmacy departments and pharmacists during disasters. Our results underscore the need for national guidance to standardize the role of pharmacists during disasters at different hospitals across the country.

According to the pharmacists' code of ethics provided by American Pharmacists Association, pharmacists have shifted to more patient-oriented approaches, and their roles are expanding beyond pharmacy windows. ${ }^{13}$ Pharmacists have obligations that extend beyond the individual to the community and society. In 2016, the FIP issued a pharmacy guideline when responding to disasters to help government and pharmacy associations plan for natural disasters. It included recommendations for implementing a national guideline through four steps: (1) prevention and risk assessment; (2) preparation, which includes a crucial aspect of expanding pharmacy legislation to allow pharmacists to expand their scopes of practice; (3) response, which is related to the safe transportation and management of medication; and (4) recovery and post incident analysis. ${ }^{5}$ In Saudi Arabia, pharmacy practice is advancing quickly, and through collaborative practice agreements, pharmacists have prescribing privileges that can be used in cases of emergency. ${ }^{14,15}$ Our study showed that pharmacists have specific roles during emergencies. All hospitals reported that pharmacists are responsible for the three following roles: maintain effective distribution and control, collaborate on medication management, and develop and maintain first-aid skills. However, the six hospitals disagreed on the remaining roles. The ASHP has published two papers describing general roles of hospital pharmacists in counterterrorism and in emergency preparedness, but specific roles in different emergencies are lacking. ${ }^{4,16}$ Moreover, Pincock et al drafted the roles of pharmacists in emergency preparedness based on authors' experiences but also emphasized the need for more efforts to refine pharmacists' specific roles and skills in emergency preparedness. ${ }^{17}$ There is a lack of training offered to pharmacists on how to be engaged in the four stages of disaster management suggested by the FIP. ${ }^{3,18}$ This gap underscores the need for initiatives to increase the quantity and quality of emergency preparedness programs to improve pharmacists' comfort and knowledge during disasters. According to Nazar Z and Nazar H, simulation was the most effective type of training. ${ }^{6}$ In Saudi Arabia, pharmacy residency programs in emergency medicine and critical care are emerging. ${ }^{14}$ Evidence has shown that the incorporation of emergency preparedness rotation for pharmacy residents improves outcomes. It helped the resident to acquire the needed skills to become an effective member of the disaster team by applying the four stages of the disaster management. Moreover, it ensured the continuity of pharmacy services during mass casualty and public health emergencies. ${ }^{19}$ 
The study's limitations include that all of the studied hospitals were in Jeddah and majority were governmental hospitals leading to selection bias, which can be limited to specific disaster types when compared to other geographical areas. Thus, our findings do not represent the entire country. Furthermore, the study survey tool was not validated, and we are not aware of any tool that describes the preparedness of any acute-care hospitals to disasters. Moreover, the survey was delivered in two ways, through email and interview, which can affect the reliability of the responses.

\section{Conclusions}

All included hospitals have installed emergency preparedness plans for the pharmacy department and the hospital, in which pharmacists are viable members. However, there was disagreement on pharmacist roles and the amount and type of stocked medications between hospitals. Future studies are needed to evaluate hospital pharmacy preparedness on a national level, reflecting upon current practices, and to develop nationwide guidance to enhance and support the preparedness of healthcare facilities.

\section{Ethical Approval}

This study was approved by the research ethics committee of King Abdulaziz University Faculty of Pharmacy (PH1443-12). Informed consents from all participants included in this study were obtained before commencing the study. This study was conducted in accordance with the principles of the Declaration of Helsinki.

\section{Disclosure}

The authors report no conflicts of interest in this work.

\section{References}

1. World Health Organization. Risk reduction and emergency preparedness: WHO six-year strategy for the health sector and community capacity development. World Health Organization; 2007. Available from: https://www.who.int/hac/techguidance/preparedness/emer gency_preparedness_eng.pdf. Accessed November 30, 2021.

2. Alyami A, Dulong CL, Younis MZ, Mansoor S. Disaster preparedness in the kingdom of Saudi Arabia: exploring and evaluating the policy, legislative organisational arrangements particularly during the hajj period. Eur J Public Health. 2020;5(1):em0053. doi:10.29333/ejeph/ 8424

3. Alruwaili A, Islam MS, Usher K. Hospitals disaster preparedness and management in the eastern province of the kingdom of Saudi Arabia: a cross-sectional study. Disaster Med Public Health Prep. 2021;4:1-8. doi:10.1017/dmp.2020.484
4. American Society of Health-System Pharmacists. ASHP statement on the role of Health-system pharmacists in emergency preparedness. Am J Health-Syst Pharm. 2012;60:1993-1995. doi:10.1093/ajhp/ 60.19 .1993

5. International Pharmaceutical Federation. Responding to disasters: guidelines for pharmacy. The Hague, the Netherlands: FIP; 2017. Available from: http://www.fip.org/files/fip/publications/2016-07Responding-to-disasters-Guideline.pdf. Accessed November 30, 2021.

6. Nazar Z, Nazar H. Exploring the experiences and preparedness of humanitarian pharmacists in responding to an emergency-response situation. Res Social Adm Pharm. 2019;16:90-95. doi:10.1016/j. sapharm.2019.03.146

7. Parajuli DR, Khanal S, Wechkunanukul KH, et al. Pharmacy practice in emergency response during the COVID-19 pandemic: lessons from Australia. Res Social Adm Pharm. 2021. doi:10.1016/j. sapharm.2021.08.013

8. Awad NI, Cocchi C. Assessment of hospital pharmacy preparedness for mass casualty events. P T. 2015;40:264-267.

9. Setlak P. Bioterrorism preparedness and response: emerging role for health-system pharmacists. Am J Health Syst Pharm. 2004;61:1167-1175. doi:10.1093/ajhp/61.11.1167.

10. Tammar A, Abosuliman SS, Rahaman KR. Social capital and disaster resilience nexus: a study of flash flood recovery in Jeddah City. Sustainability. 2020;12:4668. doi:10.3390/su12114668.

11. Khan AA, Noji EK. Hajj stampede disaster, 2015: reflections from the frontlines. Am J Disaster Med. 2016;11:59-68. doi:10.5055/ ajdm.2016.0225

12. Bhavsar TR, Esbitt DL, Yu PA, Yu Y, Gorman SE. Planning considerations for state, local, tribal, and territorial partners to receive medical countermeasures from CDC's strategic national stockpile during a public health emergency. Am J Public Health. 2018;108: S183-S187. doi:10.2105/AJPH.2018.304472.

13. Code of Ethics for Pharmacists. American Pharmaceutical Association; 2012. Available from: https://www.ashp.org/-/media/assets/policyguidelines/docs/endorsed-documents/code-of-ethics-for-pharmacists. a s h x ? 1 a =e n \& h a s h =A 124 D 6425 D 23 F D 45 F 08 325D0F2E6E18CA344C645. Accessed November 30, 2021.

14. Al-jedai A, Qaisi S, Al-meman A. Pharmacy practice and the health care system in Saudi Arabia. Can J Hosp Pharm. 2016;69:231-237. doi:10.4212/cjhp.v69i3.1561

15. Stewart D, Pallivalapila A, Thomas B, et al. A theoretically informed, mixed-methods study of pharmacists' aspirations and readiness to implement pharmacist prescribing. Int $J$ Clin Pharm. 2021;43 (6):1638-1650. doi:10.1007/s11096-021-01296-1

16. American Society of Health-System Pharmacists. ASHP statement on the role of health-system pharmacists in counterterrorism. Am $J$ Health-Syst Pharm. 2002;59:282-283. doi:10.1093/ajhp/59.3.282

17. Pincock LL, Montello MJ, Tarosky MJ, et al. Pharmacist readiness roles for emergency preparedness. Am $J$ Health-Syst Pharm. 2011;68:620-623. doi:10.2146/ajhp090659

18. Zhao Y, Diggs K, Ha D, Fish H, Beckner J, Westrick SC. Participation in emergency preparedness and response: a national survey of pharmacists and pharmacist extenders. J Am Pharm Assoc. 2021;61:722-728. doi:10.1016/j.japh.2021.05.011

19. Griebe K, Jiang C, To L, Peters M, MacDonald NC. Pharmacy emergency preparedness training as a PGY2 longitudinal rotation. Am J Health Syst Pharm. 2021;78:669-673. doi:10.1093/ajhp/ zxab044 


\section{Publish your work in this journal}

Risk Management and Healthcare Policy is an international, peerreviewed, open access journal focusing on all aspects of public health, policy, and preventative measures to promote good health and improve morbidity and mortality in the population. The journal welcomes submitted papers covering original research, basic science, clinical \& epidemiological studies, reviews and evaluations, guidelines, expert opinion and commentary, case reports and extended reports. The manuscript management system is completely online and includes a very quick and fair peer-review system, which is all easy to use. Visit http://www.dovepress.com/testimonials.php to read real quotes from published authors. 